\title{
Design analysis methods for Stirling engines
}

\author{
H Snyman \\ Department of Mechanical and Mechatronic Engineering, University of Stellenbosch, South Africa
}

T M Harms

Department of Mechanical and Mechatronic Engineering, University of Stellenbosch, South Africa

\section{J M Strauss}

Department of Electric and Electronic Engineering, University of Stellenbosch, South Africa

\begin{abstract}
Worldwide attempts are being made to increase the use of our renewable energy sources as well as to use our current fossil fuel energy sources more efficiently. Waste heat recovery forms a substantial part of the latter and is the focus of this project. Stirling technology finds application in both the renewable energy sector and in waste heat recovery. Investigating the applicability of Stirling engines in the above-mentioned fields is relevant to develop more efficient external combustion units as well as to utilize our renewable energy sources. Developing a design analysis and synthesis tool capable of optimizing Stirling powered units forms the main objective of this project. The methodology followed to achieve this, involved the application of three different methods of analysis, namely the method of Schmidt, the adiabatic analysis and the simple analysis based on a five volume approach. The Schmidt analysis is used to obtain the internal engine pressure which is a required input for the adiabatic analysis while the simple analysis introduces pumping losses and regenerator inefficiencies. These methodologies are discussed briefly in this paper. Experimental verification of the analytical data was carried out on a Heinrici Stirling engine and both the analytical data and the experimental data are presented here. Shortcomings of these methods of analysis are highlighted and an alternative approach to solve particular shortcomings is presented.
\end{abstract}

Keywords: Heinrici Stirling engine, Schmidt, adiabatic, simple analysis, five volume approach, renewable energy, waste heat recovery

\section{Nomenclature}

A Area $\left[\mathrm{m}^{2}\right]$

cc Volume $\left(\mathrm{cm}^{3}\right]$

$C_{f} \quad$ Frictional coefficient

$c_{p} \quad$ Ideal gas specific heat at constant pressure (J/kg.K]

$c_{v} \quad$ Ideal gas specific heat at constant volume [J/kg.K]

$d$ or $\boldsymbol{D}$ Diameter [m]

$d_{h} \quad$ Hydraulic diameter [m]

$d \quad$ Derivative or change in variable

$f \quad$ Frequency $[\mathrm{Hz}]$

$h \quad$ Convective heat transfer coefficient $\left[\mathrm{W} / \mathrm{m}^{2} \mathrm{~K}\right]$

$k \quad$ Thermal conductivity [W/m.K]

$m \quad$ Mass or mass flow rate $[\mathrm{kg}$ or $\mathrm{kg} / \mathrm{s}]$

$M \quad$ Mass [kg]

$N_{S T} \quad$ Stanton number

$N_{u} \quad$ Nusselt number

$p \quad$ Pressure [bar or $\mathrm{Pa}]$

$P \quad$ Power [W]

$\mathrm{Pr} \quad$ Prandtl number

PI Indicated power [W]

$P_{\text {shaft }} \quad$ Shaft power [W]

$\mathrm{Q} \quad$ Heat transfer [J]

$\dot{Q} \quad$ Heat transfer rate [W]

$R \quad$ Gas constant [J/kg.K]

$\mathrm{Re} \quad$ Reynolds number

$T \quad$ Temperature $\left[{ }^{\circ} \mathrm{C}\right.$ or $\left.\mathrm{K}\right]$ or Torque $[\mathrm{Nm}]$

u Velocity $[\mathrm{m} / \mathrm{s}]$

$V \quad$ Volume $\left[\mathrm{m}^{3}\right.$ or $\left.\mathrm{cm}^{3}\right]$

$W \quad$ Work [J]

$W_{\text {net }} \quad$ Net work [J]

\section{Greek symbols}

$\alpha \quad$ Phase angle lead of displacer piston over power piston [radians or degrees]

$\gamma \quad$ Ideal gas specific heat ratio or angle gamma [radians or degrees] 
Effectiveness [\%] or angle epsilon [radians or degrees]

$\eta \quad$ Efficiency [\%]

$\theta \quad$ Crank rotational angle [radians or degrees]

$\mu \quad$ Dynamic viscosity $[\mathrm{kg} / \mathrm{m} . \mathrm{s}]$

$\rho \quad$ Density $\left[\mathrm{kg} / \mathrm{m}^{3}\right]$

$\varpi \quad$ Angular rotational speed $[\mathrm{rad} / \mathrm{s}]$

\section{Subscripts}

C Cold side

c Compression space

ck Interface between compression space and cooler

cl Clearance space in engine

$D$ or d Displacer piston

$e \quad$ Expansion space

$\exp$ Experimental value

$f \quad$ Frictional coefficient

h Heater

$H \quad$ Hot side/end

he Interface between heater and expansion space

HE Heat exchanger

Hwall Hot end wall condition

$k \quad$ Cooler

$k r \quad$ Interface between cooler and regenerator

loss Loss energy value

mean Mean value

out Output value

$P$ or $p$ Power piston

$r \quad$ Regenerator

reg Regenerator

$r$ Interface between regenerator and heater

sw Swept volume

$w \quad$ Wall

wg Wetted perimeter

$0 \quad$ Initial or reference value

\section{Introduction}

The per capita consumption of the earth's nonrenewable energy sources, which includes gas, petroleum and coal, is related in one way or the other to the economical wealth of the society or country involved. Three-quarters of mankind's carbon dioxide production is due to the consumption of non-renewable energy sources (Lotun, 2001). The depletion of these non-renewable energy sources has become a highlighted focus point for scientists throughout the world. Studies to improve the efficiencies of machines (like automobile engines, power generation plants etc.) fuelled by non-renewable energy sources have become a highly specialized field of interest for manufacturers. The consumers' demand for "green products" has increased due to global warming and also lead to an increased effort to stop or decrease pollution.
Waste heat recovery systems form a substantial part of the methods developed to increase the efficiency of various systems. For the past five decades, research was focused on large energy system applications and groundbreaking work was done in this field. Lotun (2001) designed and evaluated a small scale waste heat recovery system for automotive applications using steam technology. He concluded that there is a need for further investigation into waste heat recovery systems for application on smaller scale automobile internal combustion (IC) engines. BMW research engineers in Munich, Germany, have utilized steam technology to harness the wasted heat energy in the exhaust systems of their cars (Sapa-dpa, 2006). A combination of modern technology and older steam technology are used to absorb the waste energy, and this is then converted to mechanical energy used to increase vehicle power output.

Stirling engines could be utilised as a possible alternative to utilise waste heat. Although the temperature ranges of waste heat in small scale automotive engines are suitable for Rankine vapour power cycles, small scale turbo generators are not yet mature (Wipplinger, 2004). This led to the idea of revisiting the old Stirling engine technology for the relatively modern heat recovery application.

Renewable energy in the form of solar electricity generators for remote applications is another possible field of application of Stirling engines. Van Heerden (2003) studied a solar-dish Stirling system and found that the technology is not mature enough at this point in time mainly due to lack of investment in product development, but that it is capable of delivering an average solar-to-electricity conversion efficiency of $24 \%$, which is higher than the current photo-voltaic systems.

\section{Stirling engine background}

A short introduction to the functioning of Stirling engines follows to contextualise the content presented here. Stirling engines are combusted externally and modern versions of this engine have a closed internal gas cycle. The 'hot-air' engine, first so referred to by the Rev. Robert Stirling, was renamed after its inventor in the early parts of the twentieth century, since it was found that gasses with lighter molecular weight such as helium and hydrogen were superior to air, and the title Stirling engine was therefore considered to be a more appropriate description than 'hot-air'.

One of the well known advantages of Stirling machines is their capability to operate on any form of thermal energy. This implies that Stirling technology could be applied in either the solar powered or waste heat recovery sectors. Market competitiveness for Stirling engines in the above mentioned fields is a topic being exploited by various research groups, as mentioned by Morrison (1999), and is 


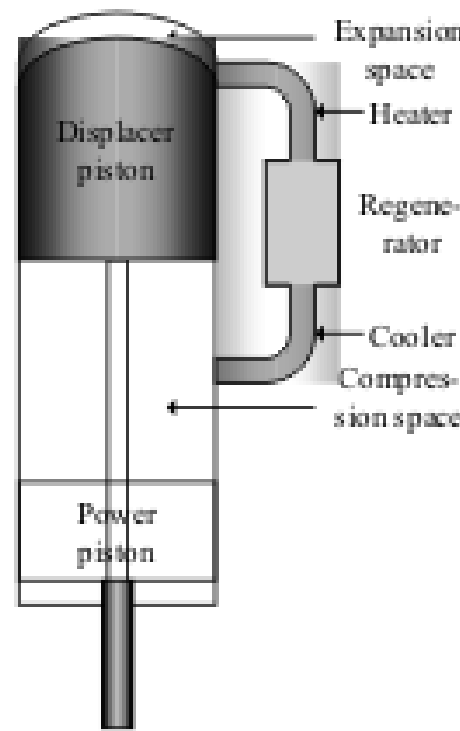

(a)

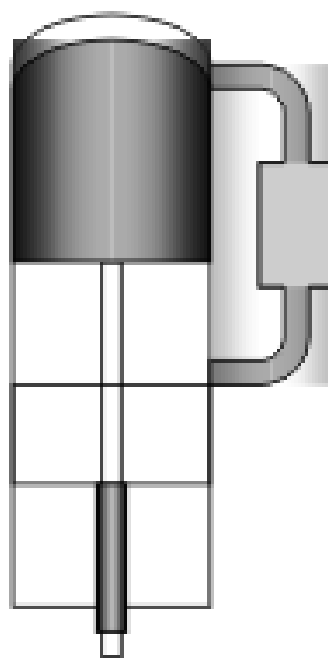

(b)

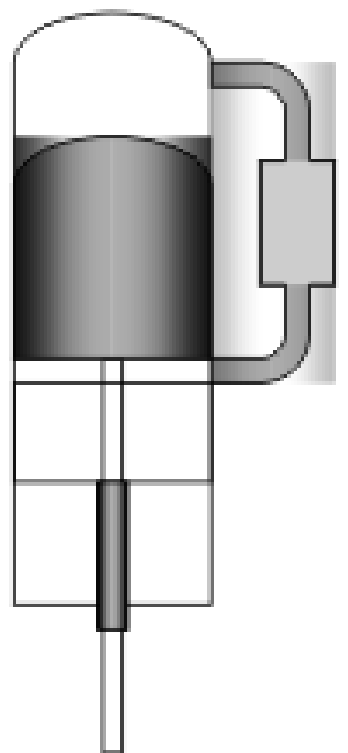

(c)

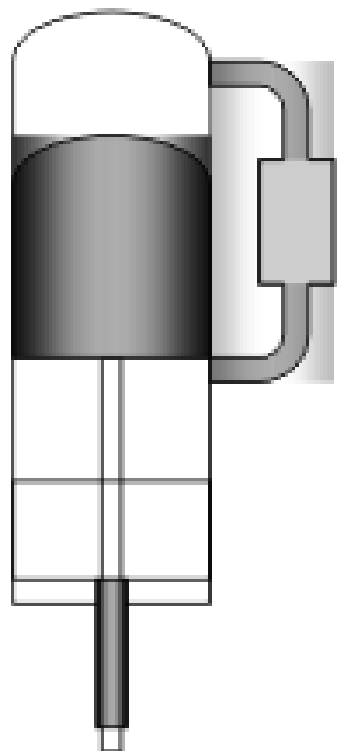

(d)

Figure 1: Stirling engine in beta configuration showing typical ideal piston displacement

an indication of the relevance and applicability of the use of this 'old technology' to solve modern problems regarding the current rate of fossil fuel depletion.

In a beta configuration similar to the engine used in this study, two pistons are present, namely the displacer and the power piston as shown in Figure 1. Although not shown in Figure 1, these two pistons are driven by a drive mechanism. Two variable volumes, namely the expansion and compression spaces and three fixes volumes, namely the hot side heat exchanger (Heater), the cold side heat exchanger (Cooler) and the regenerator constitutes the rest of the engine.

With piston position indicated in Figure 1a, the power piston is in its lowest position, the displacer piston have just moved from its lowest to its highest position displacing all of the gas to the cold space where heat is transferred from the gas to the external dump. The power piston now moves upwards while the displacer remains in its highest position, compressing the gas while it is at the lower temperature. For this process, energy is transferred from the drive mechanism to the engine. Ideally, this process is considered to be isothermal, with only the volume and the pressure that changes.

When the power piston reaches the position indicated in Figure 1b, it has reached its highest position and the displacer now starts to move downwards, effectively displacing the gas to the hot space, allowing heat to be transferred to the gas from an external source. The total volume remains constant during this process, with the temperature and hence the gas pressure that rises.

Once the displacer has reached the position as indicated in Figure 1c, i.e. just above the power pis- ton, the power piston starts to move downwards until the positions are reached as indicated in Figure $1 \mathrm{~d}$, where the power piston is again at its lowest position. During this part of the phase, the gas is expanding while it is at its highest temperature, resulting in energy being transferred from the engine to the drive mechanism. This process is also considered to be isothermal in the ideal case.

To complete the cycle, the displacer again starts to move upwards to its highest position with no change in total volume and the gas is again displaced to the cold space.

The cyclic Stirling engine can act as a thermal to a kinetic energy converter (in accordance with the second law of thermodynamics), because gas expansion occurs during higher pressure than when it is compressed, net work is obtained over one cycle, i.e. more work is delivered by the expanding gas than the work delivered to the gas during compression. This process is easily repeated at a tempo of up to $3000 \mathrm{rpm}$ for engines with helium as working gas.

The regenerator consists of layers of heat absorbent mesh or foils that act as a heat sponge to improve the efficiency of the engine. Since heat is absorbed from the gas while it is displaced from the hot side to the cold side, the amount of energy that needs to be transferred to the external dump via the cold side heat exchanger is much less and could therefore be done more effectively. When the gas is again displaced to the hot side, the gas is already heated by absorbing energy from the regenerator and less heat is needed from the external source via the hot side heat exchanger for the same net power output of the engine, hence the improved efficiency. 
Stirling engines are known to achieve conversion efficiencies of up to and even beyond $30 \%$. These are, however, well designed engines that were optimised in terms of their critical performance areas. To achieve good conversion efficiencies or alternatively good power to weight ratios or power density, several different design parameters need to be optimised. These include, amongst others, operating pressure, dimensional aspects such as bore to maximum piston displacement ratio, heat exchanger and regenerator design and void volume minimisation.

\section{Stirling engine analysis \\ 3.1 Overview}

The Stirling Engine Analysis (SEA) program employed during this investigation is based on the program and methodology developed by Berchowitz and Urieli (1984). It formed part of a course presented by Urieli at the Ohio University, Athens, Ohio. The simulation program presented by Berchowitz and Urieli (1984) was developed for an alpha type Stirling engine and included different heat exchanger geometries and operating conditions. The Heinrici Stirling engine (HSE) used in this investigation is, however, a beta configuration engine with heat exchangers, which is quite different (refer to Figure 1) to that presented by Berchowitz and Urieli (1984).

Berchowitz and Urieli (1984) presented three methods of analysis namely, Schmidt or isothermal analysis, adiabatic analysis and simple analysis. The latter two methods find application in the Stirling engine design and analysis field, while the Schmidt method is mostly used during design synthesis. The Schmidt analysis is the most simplified of the three and forms the initialization procedure of the other two methods. The adiabatic analysis is more complex but is widely known to be a more realistic simplification of the complex Stirling cycle. The simple analysis serves as an extension of the adiabatic model i.e. non-ideal effects are incorporated by subtracting them from the results obtained from the adiabatic analysis. Non-ideal effects considered include fluid friction or pumping losses, non-ideal heat exchangers and non-ideal regeneration effects. These methods of analysis only predict the capabilities of the engine based on the performance of the thermodynamic cycles and do not incorporate the drive mechanism of the engine (the drive mechanism is however used to obtain the volume variation and rate of change thereof within the engine, since these are a function of the engine configuration).

Table 1 lists the required user defined input parameters for the adiabatic analysis of the HSE analysis. Since the internal gas mass of the engine is a key parameter during simulation procedures and it is difficult, if not impossible, to obtain before- hand, the approach used during these simulation procedures is to specify a required mean operating engine pressure. The Schmidt analysis is then used to determine the mass of the operating fluid of the engine. The Schmidt analysis requires the following seven design parameters: mean operating pressure $p_{\text {mean }}$, power and displacement piston swept volumes $V_{P}$ and $V_{D}$ respectively, clearance volume $V_{c l}$, hot and cold side temperature $T_{H}$ and $T_{C}$ respectively, and phase angle lead á of displacement piston over power piston. These seven design parameters are only a variation of those listed in Table 1. Other required input parameters for the adiabatic model are based on the configuration and operating conditions of the engine.

Table 1: User defined input parameters for HSEA

\begin{tabular}{ll}
\hline Variable & \multicolumn{1}{c}{ Description } \\
\hline$V_{k}, V_{r}$ and $V_{h}$ & Defined by heat exchanger geometry \\
\hline$R, c_{p}, c_{v}$ and $\tilde{a}$ & Defined by the choice of operating fluid \\
\hline$T_{k}, T_{r}, T_{h}$ and $f$ & Defined by operating conditions \\
\hline$V_{e}, V_{c}, d V_{e}$ & Analytical function of crank angle è i.e. \\
and $d V_{c}$ & depends on the drive mechanism \\
\hline$p_{\text {mean }}$ & Predefined user input \\
\hline
\end{tabular}

This method to obtain the mass of operating fluid was presented by Berchowitz and Urieli (1984), however, for the analysis done on the Heinrici engine this method has been altered slightly. It starts out the same but at the end of the simulation, the average engine pressure is re-calculated and compared to the original user defined mean operating pressure. The difference is then used to scale the results (including engine pressure) in order to have the beginning and end mean operating pressures the same.

\subsection{Method of solution for adiabatic model}

The engine is considered as a five component or five cell unit with the expansion and compression cells considered to be adiabatic, hence the name adiabatic analysis. Energy is only transferred across the interfaces by means of enthalpy transferred to and from the working spaces in terms of mass flow and upstream temperature, while the heater and the cooler provides the energy source and sink, respectively. Figure 2 illustrates the nomenclature for enthalpy flow through a simplified alpha type engine configuration, where the arrows represent the interfaces between cells. Single suffixes $(c, k, r$, $h, e)$ represent the five engine cells and double suffixes $(c k, k r, r h, h e)$ represent the four interfaces between cells. Figure 2 also indicates the assumed temperature gradients in the five engine cells.

When considering the equation set for the adiabatic model, of which a summary is presented in 

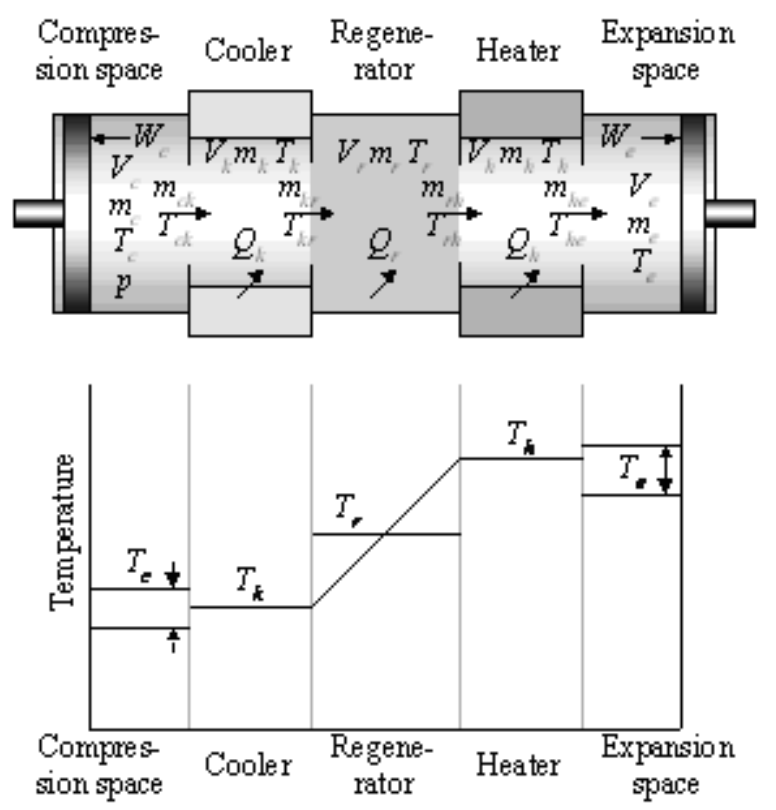

Figure 2: Nomenclature of simplified alpha type engine

Source: Berchowitz and Urieli (1984)

Appendix $A$, it is found that there are twenty-two variables and sixteen derivatives to be solved for a single cycle. They are:

- $T_{c}, T_{e}, Q_{k}, Q_{r}, Q_{h}, W_{e}, W_{c}$ - seven derivatives to be integrated

- $W, p, V_{e}, V_{c}, m_{c}, m_{k}, m_{r}, m_{h}, m_{e}-$ nine analytical variable and derivatives

- $T_{c k}, T_{h e}, m_{c k}, m_{k r}, m_{r h}, m_{h e}-$ six conditional and mass flow variables

The problem is treated as a quasi steady-flow system, which implies that over each integration interval the four mass flow variables (equation (A.4) in Appendix A) remain constant and there are no acceleration effects. The problem thus becomes a set of seven ordinary differential equations to be solved simultaneously. The approach to solving these differential equations is to formulate them as an initial value problem. With the initial values of the variables known, the equations are integrated from that initial state by means of stepwise fourthorder Runge-Kutta integration over the complete cycle. The expansion and compression space temperatures are thus initially specified and can be solved through as many cycles as necessary to attain cyclic convergence (for most cases between five and ten cycles/iterations are sufficient).

Governing equations for the adiabatic model are derived by applying the energy equation:

$$
\begin{aligned}
& d Q+c_{p} T d m=d W+c_{v} T d m \text { or } \\
& d Q=d W-R T d m
\end{aligned}
$$

and the equation of state (also shown in differential form), namely:

$$
\begin{aligned}
& p V=m R T \\
& d p / p+d V / V=d m / m+d T / T
\end{aligned}
$$

to each of the five engine components. The mass conservation law (continuity equation) is then used to link the resulting equations.

\subsection{Modelling of non-ideal effects in simple analysis}

The simple analysis introduces the effects of nonideal regeneration, non-ideal heat exchangers and pumping losses. The effect of non-ideal regeneration is modelled by using the number of transfer units (NTU) method, with NTU defined in terms of the Stanton number, namely:

$$
N T U=N_{S T}\left(A_{w g} / A\right) / 2
$$

The Stanton number is obtained by:

$$
N_{S T}=h / \rho u c_{p} .
$$

The factor 2 in equation (3) stems from the fact that the Stanton number is defined for heat transfer from a gas stream to a matrix only, whereas for the cyclic nature of the regenerator heat is also transferred from the matrix to the gas stream.

The regenerator effectiveness can then be obtained by the following equation, namely:

$$
\varepsilon_{\text {reg }}=\begin{gathered}
\text { NTU } \\
(1+N T U)
\end{gathered} \text {. }
$$

The effectiveness of the heater and cooler can be evaluated in much the same way as for the regenerator i.e. by means of NTU. The heat exchanger effectiveness then becomes:

$$
\varepsilon H E=1-e^{-N T U} .
$$

In Figure 3 showing the temperature variations as considered for the simple analysis, it can be seen that for the real heater and cooler the mean effective temperatures in the heater and cooler are respectively lower and higher than the respective heat exchanger wall temperatures. This implies that the engine is operating between lower temperature limits than originally specified which effectively reduces the performance of the engine.

The simple analysis for the heater and cooler iteratively determines these lower operating temperature limits by using the convective heat transfer equations. Values for the heater heat transfer $\left(Q_{h}\right)$ and cooler heat transfer $\left(Q_{k}\right)$ are obtained from the adiabatic analysis.

From the basic heat transfer equation, namely:

$$
Q=h A_{w g}\left(T_{w}-T\right)
$$

the respective heater and cooler gas temperatures 


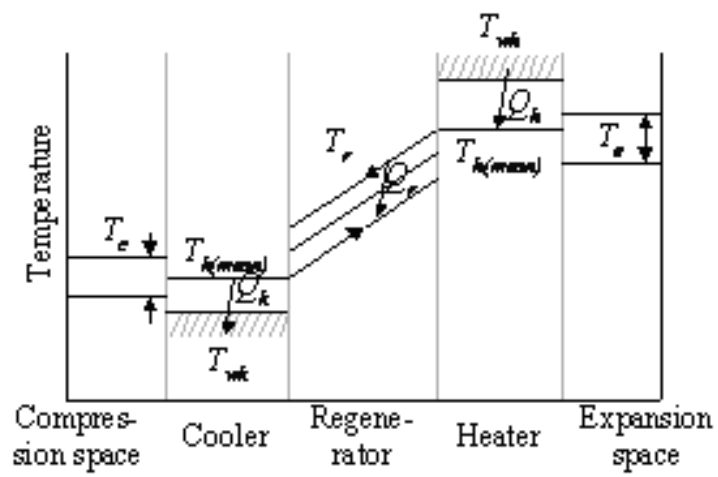

Figure 3: Real heater, cooler and regenerator effective temperatures for simple analysis Source: Berchowitz and Urieli (1984)

can be found, namely:

$$
\begin{aligned}
& T_{k}=T_{w k}-f Q_{k} /\left(h_{k} A_{w g k}\right) \\
& T_{h}=T_{w h}-f Q_{h} /\left(h_{h} A_{w g h}\right)
\end{aligned}
$$

(the units of $\dot{Q}$ are reduced, i.e. $f Q=\dot{Q}$, in order to obtain the heat transfer for a single cycle, hence being able to evaluate heater and cooler temperatures during each iterative cyclic analysis).

In practical engines, fluid friction associated with the flow through the heat exchangers will result in a pressure drop across the heat exchangers that will in turn reduce the output power of the engine. This is referred to as 'pumping loss'. The pressure drop across the three heat exchangers is evaluated with respect to the compression space and the summation thereof $(\Sigma \Delta \mathrm{p})$ is then used to reduce the total engine work term, $\mathrm{W}$, i.e.

$W=\oint p\left(d V_{e}+d V_{c}\right)-\oint \sum \Delta p d V_{e}=W_{i}+\Delta W$

where $W_{i}$ is the work done per cycle as obtained from the ideal adiabatic analysis, and $\Delta W$ is pumping loss per cycle converted to work loss with

$\Delta W=\int_{0}^{2 \pi}\left(\sum_{i=1}^{3} \Delta p_{i} \frac{d V_{e}}{d \theta}\right) d \theta$,

fluid friction loss (or $\Delta p$ ) is evaluated as follows, namely:

$\Delta p=\frac{-2 C_{f} \operatorname{Re} \mu u V}{d_{h}^{2} A}$,

with

$C_{f} \equiv \frac{\tau}{0.5 \rho u^{2}}$

and

$\operatorname{Re}=\frac{\rho u d_{h}}{\mu}$.
Berchowitz and Urieli (1984) state that due to the highly oscillating nature of the flow within Stirling engines it is reasonable to assume that the flow would always be turbulent. Organ (1997) mentions that this is still a mere assumption in order to be able to analyze the actually ill understood situations within Stirling engines. Organ stated: 'The general case of cyclically reversing, compressible flow with friction, heat transfer and pressure swing is not understood. Regenerator and Stirling engine design thus remains dependant on the use of steady flow correlations and subject to the arbitrary rationalizations involved in applying these.'

\subsection{HSE topology and nomenclature}

Hargreaves (1991) states that various engineers were building Stirling machines up until 1900, of which Heinrici in Germany was one. He mentions that Heinrici, however, continued to make their simple, inefficient but reliable small Stirling engine up to the mid 1930's. The Stirling engine used during experimental verification of simulated results was one of the variations of the Stirling engines developed by Heinrici. It is a beta type engine configuration with a fly-wheel crank drive-mechanism. Figure 4a shows a transparent side view of the HSE.

The methodology developed by Berchowitz and Urieli (1984) utilizes a five volume approach similar to that indicated for the simplified alpha configuration engine shown in Figure 2. The Heinrici Stirling engine (HSE) considered here, however, does not have a regenerator or specific internal heater and cooler heat exchangers as is the case for the simplified model. For this reason, the internal volumes of the HSE are defined in such a way that they satisfy the five volume approach. Figure $4 \mathrm{~b}$ shows the five virtual volumes defined in the HSE as well as the basic layout of the beta configuration HSE used for experimental verification of the simulated results. Another more important reason for defining the five virtual volumes in the HSE instead of applying a more simple three volume methodology results from the fact that modern Stirling engines have a clear five volume layout as this provides for higher heat transfer and thus increased thermal efficiency as well as increased power output. Developing a three volume methodology is therefore wasteful when it is required to analyze five volume engines in future.

The five volumes in Figure $4 \mathrm{~b}$ are defined as follows:

1. Heater volume $\left(V_{h}\right)$

2. Regenerator volume $\left(V_{r}\right)$

3. Cooler volume $\left(V_{k}\right)$

4. Compression space volume $\left.\left(V_{c}\right) .4 \mathrm{cl}\right)$ Compression space clearance volume $\left(V_{c l c}\right)$

5. Expansion space volume $\left.\left(V_{e}\right) .5_{\mathrm{cl}}\right)$ Expansion space clearance volume $\left(V_{c l e}\right)$

Although the HSE has no real regenerator, it is 


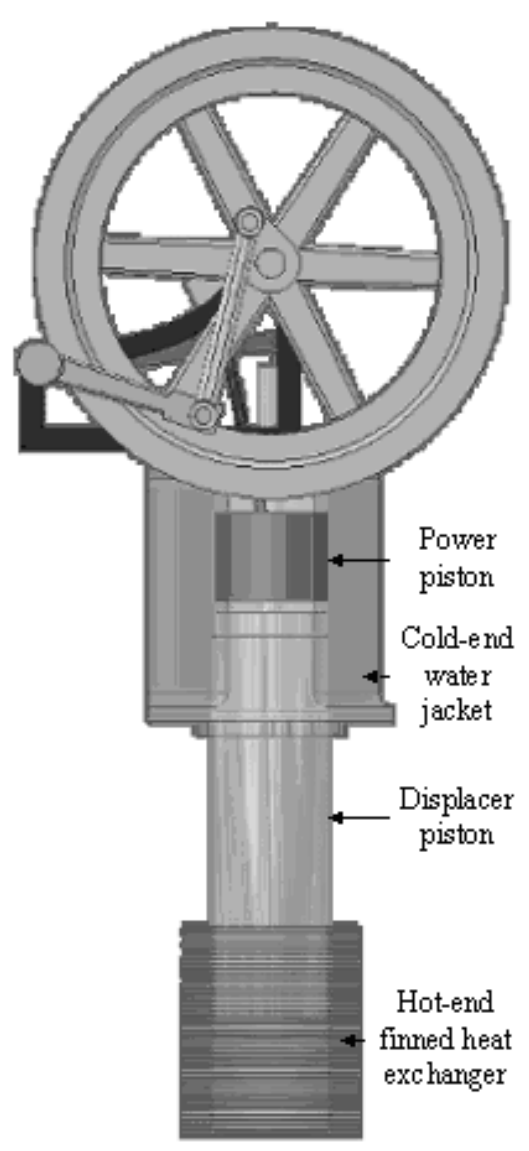

(a)

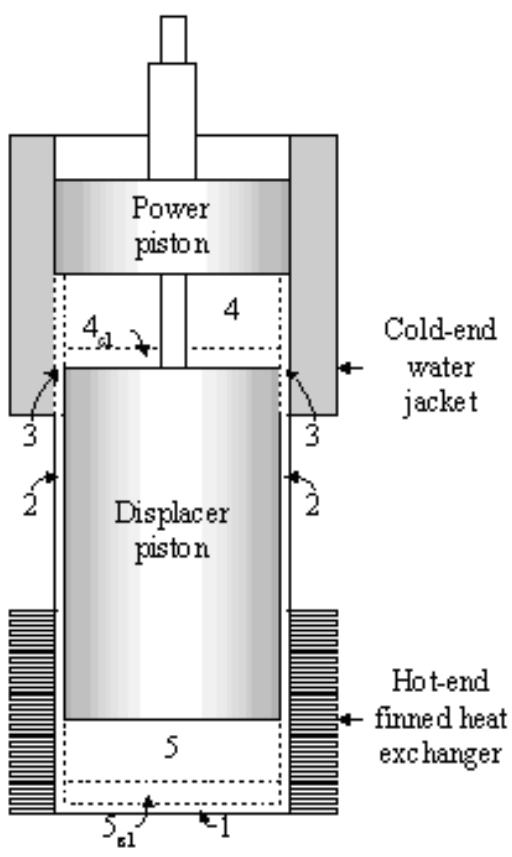

(b)

Figure 4: HSE volume definitions and transparent side view

given a virtual volume and it is set to be $100 \%$ porous. In reality the walls of the annulus formed between the cylinder sleeve and the displacer piston have some regenerative effect, but this is assumed negligible for this engine.

\section{Simulated HSE performance}

The HSE was analysed by using the Schmidt, adiabatic and simple methods of analysis presented by Berchowitz and Urieli (1984). Experimentally measured data is used as user defined operating conditions during analyses performed on the HSE in order to verify accuracy of simulations. These operating conditions are listed in Table 2.

Table 2: Operating conditions for HSE

\begin{tabular}{lcc}
\hline \multicolumn{1}{c}{ Description/variable } & Value & Unit \\
\hline Mean operating pressure $\left(p_{\text {mean }}\right)$ & 1.148 & bar \\
\hline Cold side wall temperature $\left(T_{k}\right)$ & 46 & ${ }^{\circ} \mathrm{C}$ \\
\hline Hot side wall temperature $\left(T_{h}\right)$ & 448 & ${ }^{\circ} \mathrm{C}$ \\
\hline Operating frequency & 73.3 & $\mathrm{rpm}$ \\
\hline
\end{tabular}

Table 3 lists the numeric results obtained by applying the simple analysis on the Heinrici engine. Non-ideal heat exchangers and regeneration as well as pumping losses caused by fluid friction are con- sidered. The first section of Table 3 presents the temperature gradients within the heater and cooler heat exchangers, while the second section presents the engine's performance before consideration of frictional losses. Specifications of non-ideal regeneration as well as actual engine performance, after work loss due to friction, are presented in the final two sections of the table. Note that the power output is the total predicted power output of the engine and not only the cyclic power delivered i.e. the cyclic work is multiplied by the operating frequency to obtain the total power output of the engine. This applies to all power relevant (heat or output power) values displayed in the table below. Also note that the simulated power is only a function of the thermodynamic cycle and not of the engine's drive mechanism. The user defined input temperatures are stated alongside the simulated results for the non-ideal heat exchangers for simplicity.

When considering the $\mathrm{p}-\mathrm{V}$ diagram for the simple analysis presented in Figure 5 below, it is clear that the consideration of the non-ideal heat exchangers caused a larger deviation from the ideal $\mathrm{p}-\mathrm{V}$ diagram than that of the adiabatic analysis. Reader (1983) states that this phenomenon occurs due to the fact that the cylinder walls do not provide a heat transfer medium of sufficient high conduc- 
Table 3: Numeric results from simple analysis of HSE

\begin{tabular}{|c|c|c|}
\hline Description & Value & Unit \\
\hline \multicolumn{3}{|l|}{ Temperature effects of non-ideal heat exchangers } \\
\hline User defined hot side wall temperature ( $T_{h}$-wall) & 448 & ${ }^{\circ} \mathrm{C}$ \\
\hline Simulated hot side gas temperature ( $\left.T_{h \text {-gas }}\right)$ & 428.9 & ${ }^{\circ} \mathrm{C}$ \\
\hline User defined cold side wall temperature $\left(T_{k}\right.$-wall $)$ & 46 & ${ }^{\circ} \mathrm{C}$ \\
\hline Simulated cold side gas temperature ( $T_{k}$-gas) & 63.7 & ${ }^{\circ} \mathrm{C}$ \\
\hline \multicolumn{3}{|l|}{ Engine performance results } \\
\hline Pressure correction factor & $-0.0012^{*}$ & - \\
\hline Gas mass & & $0.6606 \mathrm{~g}$ \\
\hline Thermal efficiency of thermodynamic cycle & 38.43 & $\%$ \\
\hline Power output of thermodynamic cycle & 14.25 & W \\
\hline Heat power added by heater & 37.1 & W \\
\hline Heat power rejected by cooler & -22.82 & $\mathrm{~W}$ \\
\hline \multicolumn{3}{|l|}{ Results of non-ideal regenerator } \\
\hline Regenerator effectiveness & 74.59 & $\%$ \\
\hline Regenerator wall conductance & 0.7859 & $\mathrm{~W} / \mathrm{K}$ \\
\hline Regenerator net enthalpy loss & 47.53 & $\mathrm{~W}$ \\
\hline Regenerator wall heat loss & 315.96 & $\mathrm{~W}$ \\
\hline \multicolumn{3}{|l|}{ Results from fluid frictional losses } \\
\hline Pumping loss & 0.2031 & W \\
\hline Actual power of thermodynamic cycle & 14.0475 & $\mathrm{~W}$ \\
\hline Actual heat power required & 400.57 & $\mathrm{~W}$ \\
\hline Actual efficiency & 3.51 & $\%$ \\
\hline
\end{tabular}

tance to ensure constant gas temperatures within the cylinders, thus causing deviation from the isothermal conditions and hence the consideration of the non-ideal heat exchangers. Reader (1983) also mentions that the deviation is more pronounced on the hot-side of the engine than on the cold-side, as illustrated by Figure 5. The area included within the $\mathrm{p}-\mathrm{V}$ diagram represents the developed engine work per cycle. It is not very obvious that there is a significant difference in area, but upon comparison of the results obtained for the adiabatic and simple analyses (refer to Table 4) it is clear that the power predicted by the simple analysis $(14.05 \mathrm{~W})$ is less than that of the adiabatic analysis $(16.18 \mathrm{~W})$. This is expected as the simple analysis gives a better approximation of the practical conditions existing within Stirling engines.

Table 4: Comparison of HSEA results from the 3 methods

\begin{tabular}{lccc}
\hline $\begin{array}{l}\text { Method of } \\
\text { analysis }\end{array}$ & $\begin{array}{c}\text { Gas mass } \\
(\mathrm{g})\end{array}$ & $\begin{array}{c}\text { Power } \\
(\mathrm{W})\end{array}$ & $\begin{array}{c}\text { Efficiency } \\
(\%)\end{array}$ \\
\hline Schmidt & 0.66054 & 21.81 & 55.76 \\
\hline Adiabatic & 0.672 & 16.2 & 42.1 \\
\hline Simple & 0.6606 & $14.21(14)$ & $38.4(3.51)$ \\
\hline
\end{tabular}

Figure 6 shows the cyclic pressure variation in the Heinrici engine as obtained from the simple analysis. It is assumed that the internal pressure is the same throughout the engine. This implies that the pressures in the five cells of the engine are the same. The pressure variation of the adiabatic analysis is also shown in Figure 6. Note the difference in relative magnitude as well as the phase similarity between the two curves. The difference in magnitude can be ascribed to the pressure loss (from work loss simulation) taken into account by the simple analysis. Incorporating this work loss in the simple model thus leads to a lower operating pressure ratio which provides a more correct approximation of the real engine.

Figure 7 below shows the cyclic energy flow in the three heat exchangers of the engine as well as the total work done per cycle. Values for the heat rejected by the cooler $\left(Q_{k}\right)$ and heat added by the heater $\left(Q_{h}\right)$ as well as total work done $(W)$ is indicated (see Table 4 for numeric results.). Note the difference in magnitude of energy flow between the regenerator and that of the heater and cooler. Also note that the total cyclic energy flow through the regenerator sums to zero for the ideal case. The energy flow in the regenerator is of the order of five times more than that of the heater and six times 


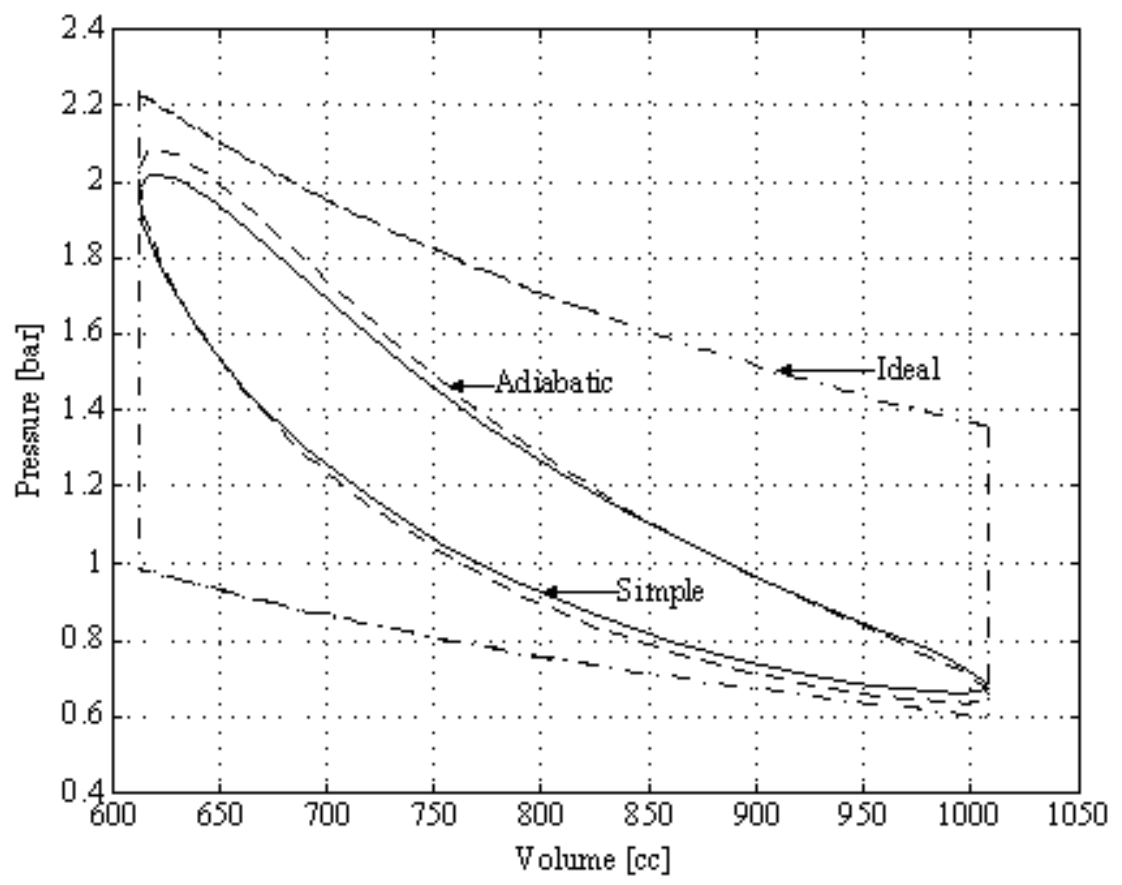

Figure 5: $\mathrm{p}-\mathrm{V}$ Diagram: Ideal, adiabatic and simple analysis

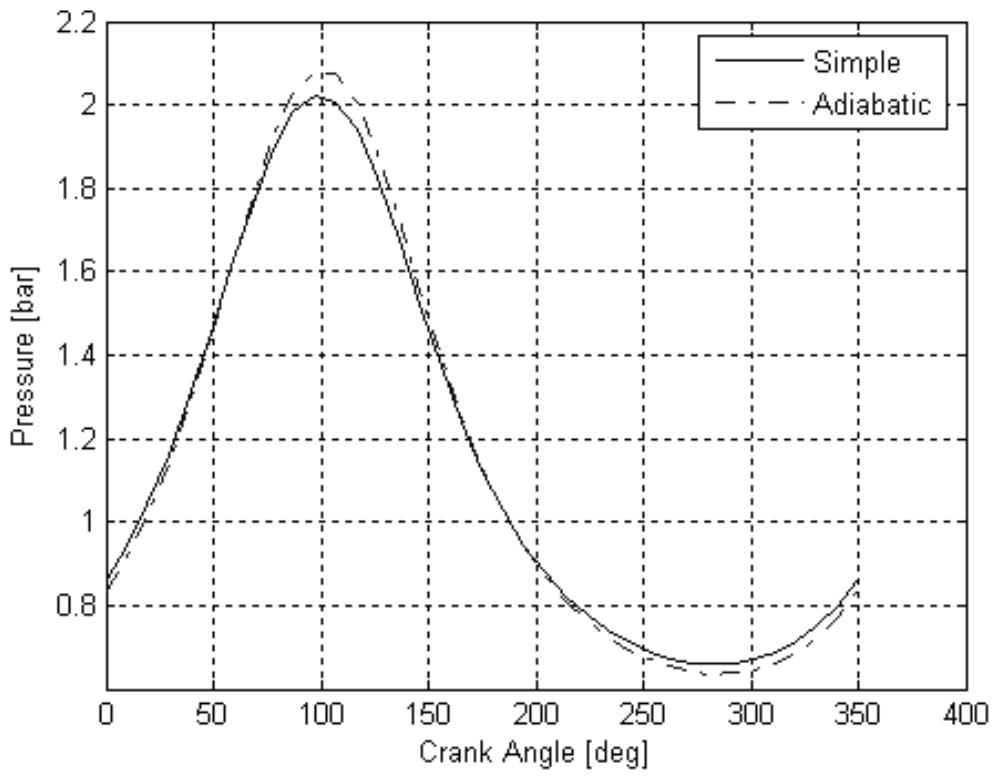

Figure 6: Pressure variation: Adiabatic and simple analysis

more than that of the cooler i.e. the heat transfer capacities of the heater and cooler are respectively five and six time less than that of the regenerator. In Table 5 below, the maximum and minimum values of the energy flow within the three heat exchangers are listed. This result is in accordance with the recommendation by Reader (1983) who stated that the regenerator must be able to deal with four to five times the heat load of the heater. Reader mentions that, should the design fail to meet this requirement an extra heat load will be placed on the other heat exchangers which will reduce the internal operating temperature difference and thus reduce engine power.
Table 5: Maximum and minimum thermal load on the 3 heat exchangers

\begin{tabular}{lcc}
\hline Heat exchanger & $\begin{array}{c}\text { Maximum } \\
(J)\end{array}$ & $\begin{array}{c}\text { Minimum } \\
(J)\end{array}$ \\
\hline Heater cyclic energy flow $\left(Q_{h}\right)$ & 31.2 & -6.1 \\
\hline Cooler cyclic energy flow $\left(Q_{k}\right)$ & 0 & -23.1 \\
\hline Regenerator cyclic energy flow $\left(Q_{r}\right)$ & 145.8 & -7.4 \\
\hline
\end{tabular}

Figure 8 shows the instantaneous mass flow rates in each engine cell. Keep in mind that the quasi steady-flow assumption implies that at any given moment the engine pressure is constant throughout the engine. The question regarding 


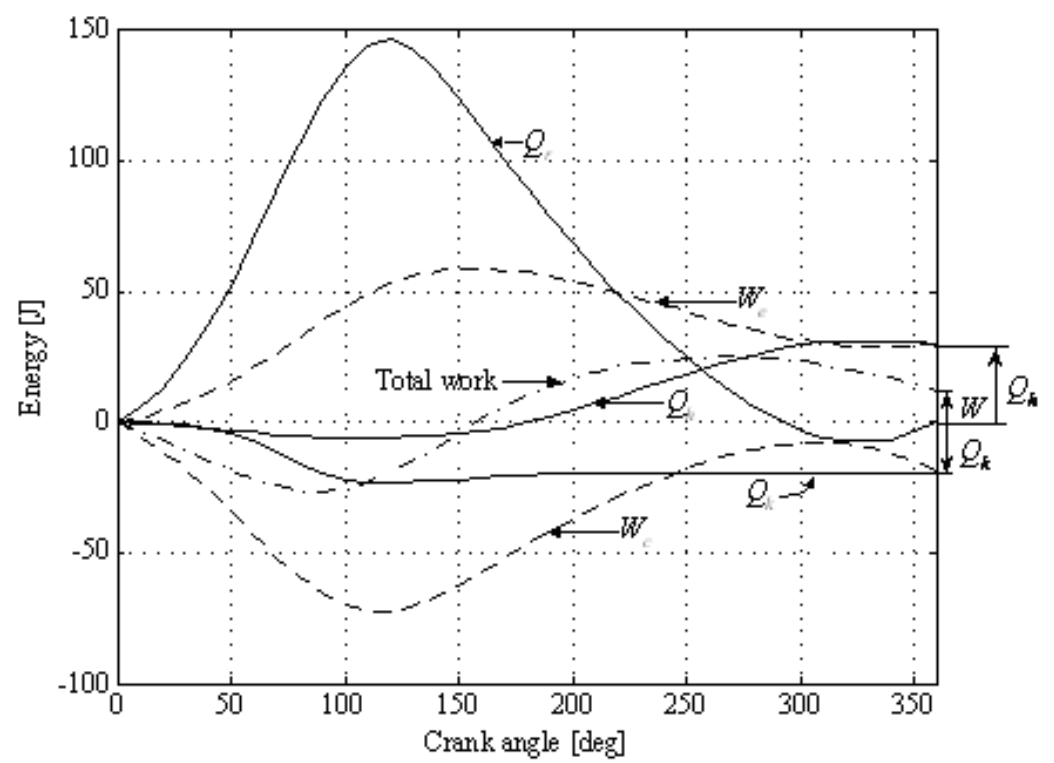

Figure 7: Cyclic energy flow within each engine cell

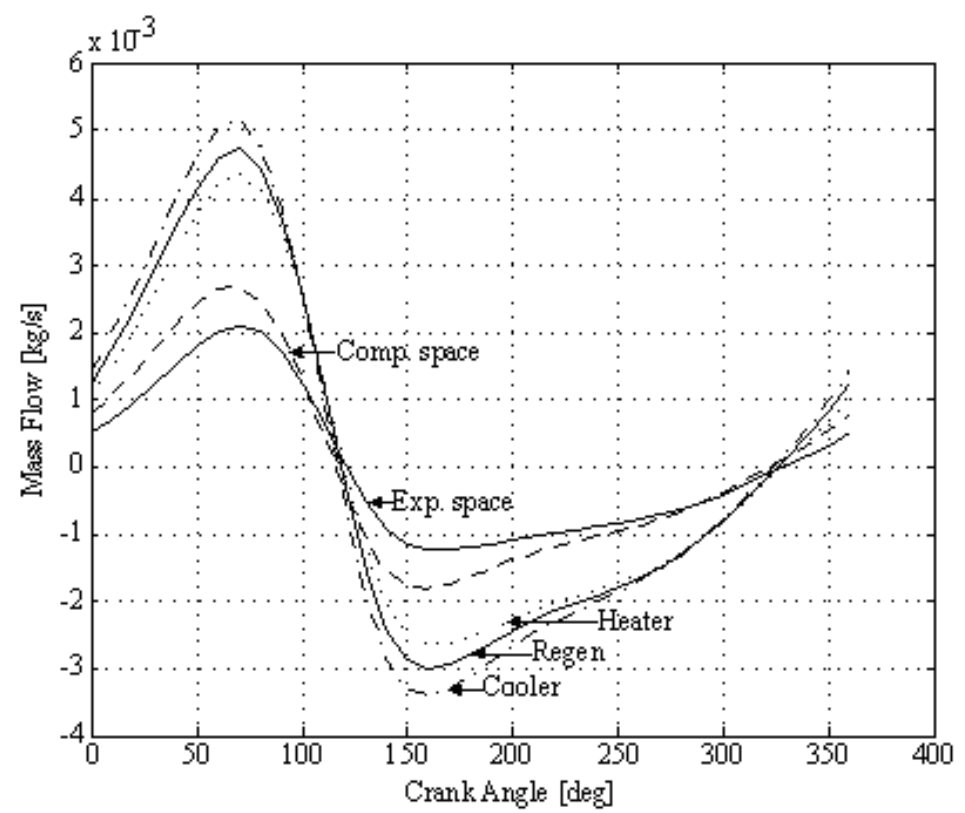

Figure 8: Mass flow rate within each cell

where the mass flow comes from arises. The instantaneous mass in each engine cell is calculated using the equation of state, similarly the mass accumulation within each cell is obtained by applying the energy equation to the five cells and substituting the ideal gas relations. The mass flow rate within each cell is then obtained as a function of the direction of flow and depends on the mass flow rate of the preceding engine cell (refer to Appendix A for a summary of the adiabatic equation set, under the 'equations for masses' section).

Figure 9 shows the instantaneous mass of gas in each cell of the engine. The pressure variation is also shown to indicate the interaction between mass and pressure within the heater, cooler and regener- ator cells. Note that the graph representing the instantaneous mass of gas in the compression space is almost a direct mirror image of that of the expansion space. This indicates that most of the gas is within the compression space when compression occurs (heat rejection). Similarly for the expansion space most of the gas is within the expansion space when expansion occurs (heat addition). Increase in pressure is caused by expansion which occurs as soon as the majority of the operating fluid is contained within the expansion space and is heated. Hence, the similarity between the trends of the pressure and expansion space mass curves. This is easily explained when considering the equation of state for an ideal gas; increase in mass and temper- 


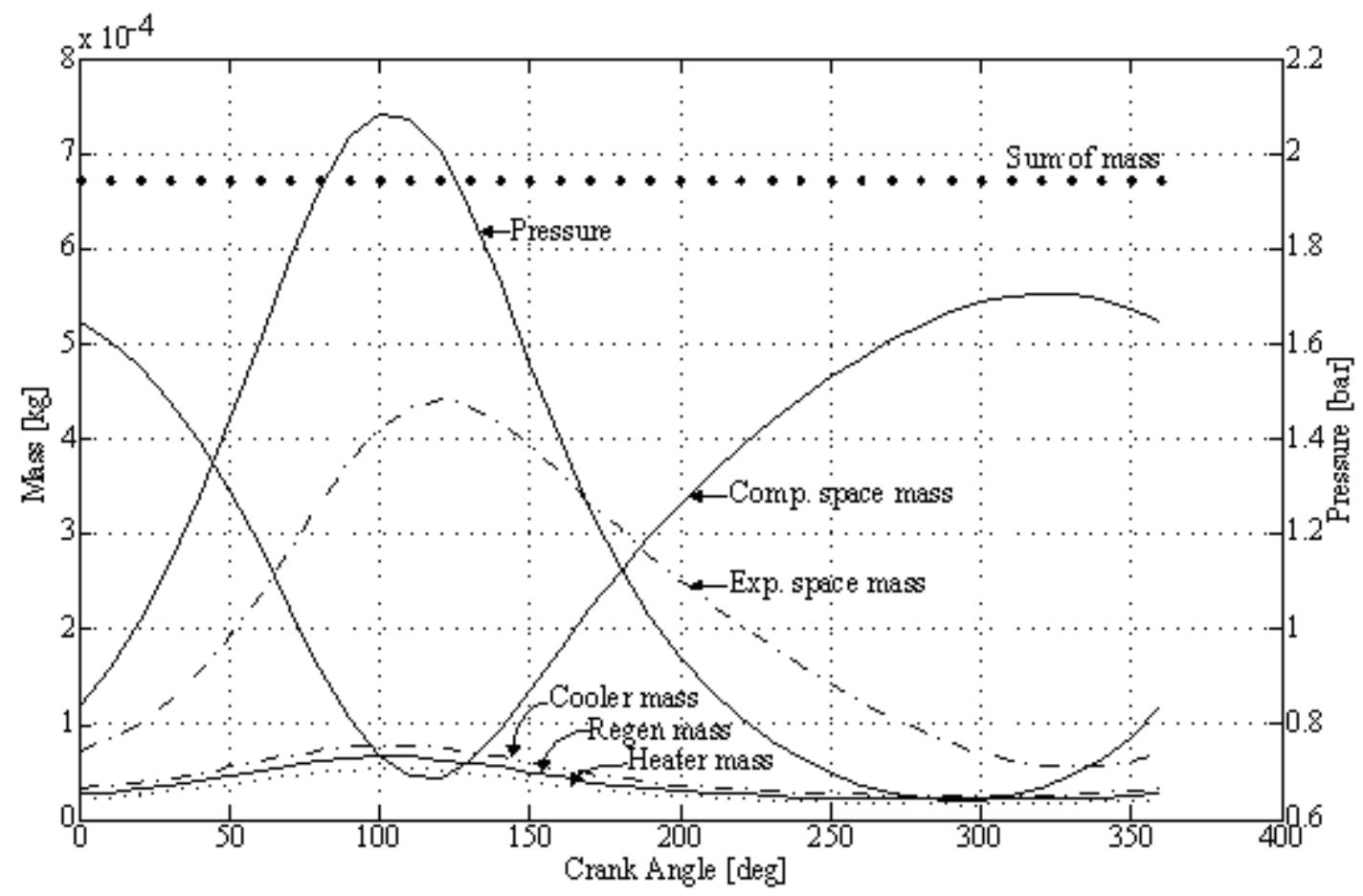

Figure 9: Instantaneous mass of gas in each engine cell

ature at the same volume constitutes an increase in pressure.

Figure 10 shows the pressure drop across the three heat exchangers. Note the phase similarity of the pressure drop between the heat exchangers. Also note the relative magnitude between the pressure drop across the regenerator and that across the heater and cooler. The regenerator is clearly the obstruction in the flow field causing the highest resistance to mass flow i.e. the regenerator governs the pumping loss in the engine. The regenerator of the Heinrici engine is almost non-existing (as mentioned previously), since it has no regenerative matrix (hence a very low heat storing capacity). This is, however, one of the reasons for the relatively low pressure drop across the regenerator.

Note that the pressure drop in each engine cell is not calculated as part of the simulation procedure. It is only calculated after the convergence of the simulation procedure in order to evaluate the pumping loss of the engine.

Figure 11 shows the temperature fluctuation of

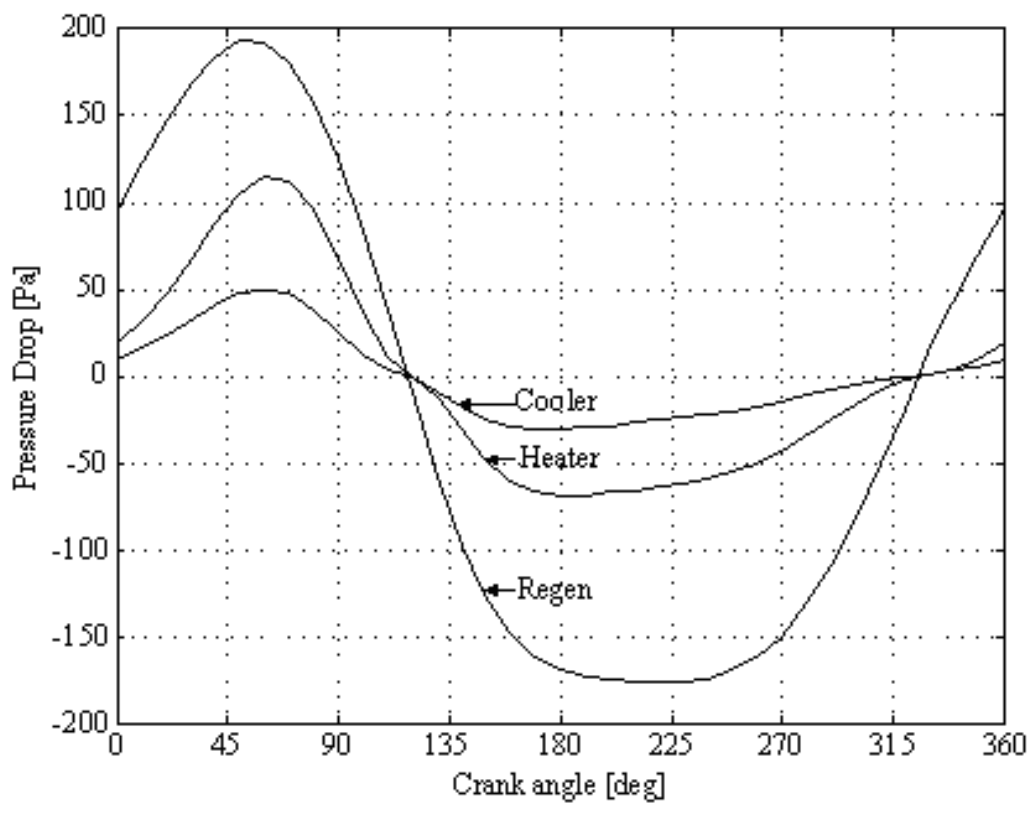

Figure 10: Cyclic pressure drop over each engine cell 


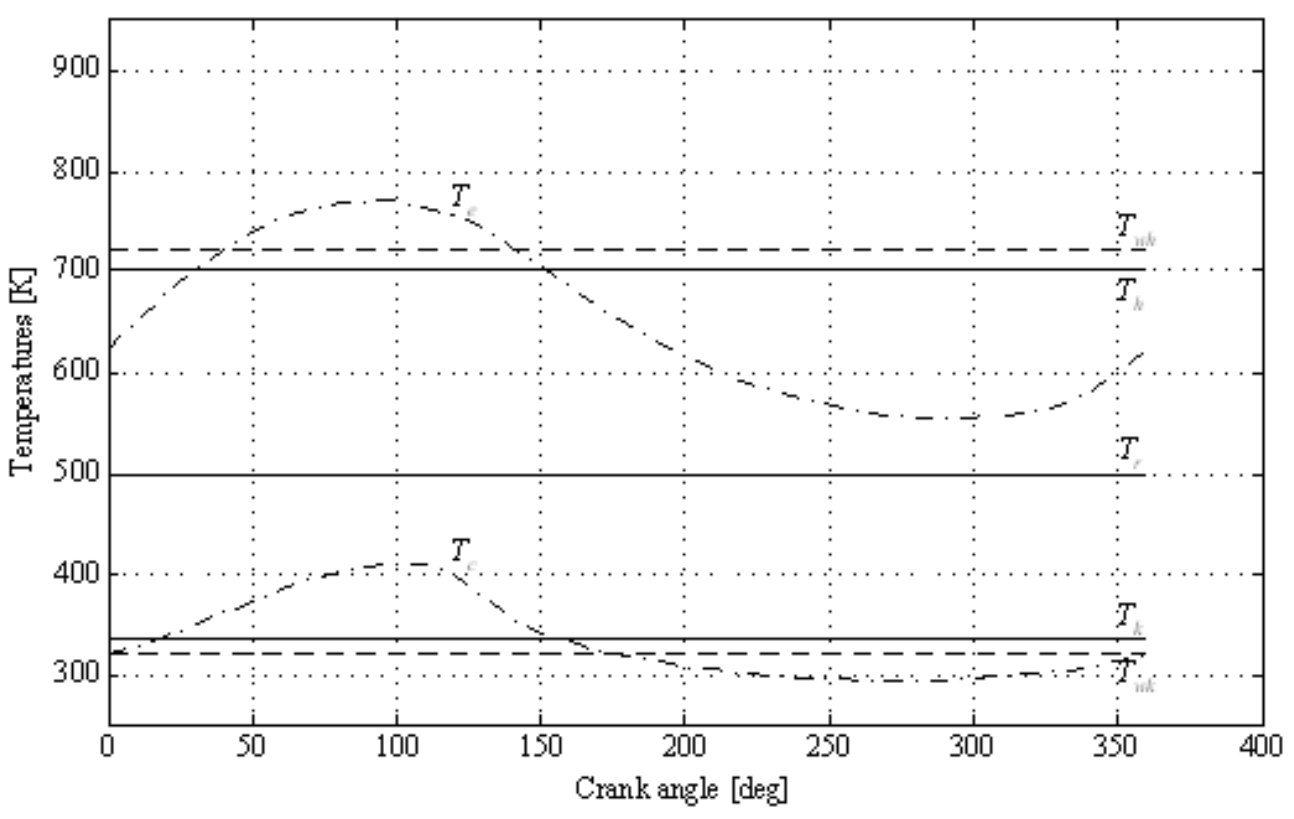

Figure 11: Temperature fluctuation: Simple analysis

the expansion $\left(T_{e}\right)$ and compression spaces $\left(T_{c}\right)$ as well as the constant regenerator temperature as obtained from the simple analysis of the Heinrici Stirling engine. The simple analysis incorporates the effect of non-ideal heat exchangers thus introducing a temperature gradient between the wall and the gas within the heater and cooler heat exchangers. Note that the non-ideal heat exchanger simulation indicates that the hot side gas temperature $\left(T_{h}\right)$ is lower than the user defined hot side wall temperature $\left(T_{w h}\right)$. Similarly, the cold side gas temperature $\left(T_{k}\right)$ is higher than the user defined wall temperature $\left(T_{w k}\right)$. This is in fact the case in actual Stirling engines and implies that the engine operates between narrower temperature limits, thus producing less power than predicted by the adiabatic and isothermal models. The user defined wall temperatures are also shown in Figure 11. These are the same temperatures as the hot $\left(T_{h}\right)$ and cold $\left(T_{k}\right)$ side temperatures used for the adiabatic analysis and are listed in Table 3.

Table 4 compares the results obtained from simulation of the HSE using the three different methods. Note that for the simple analysis in Table 4 the results only incorporate the non-ideal heater and cooler heat exchangers effects, while the value shown in brackets includes the effects of pumping loss and non-ideal regeneration.

\section{Experimental HSE performance}

\subsection{The HSE experimental test arrangement}

The experimental test arrangement comprised the following equipment:

- Heinrici Stirling engine

- Continuous combustion unit (CCU)

- Thermocouples (internal hot/cold-side gas tem- perature and external source and sink measurements)

- Pressure transducers (expansion space pressure measurement)

- Torque transducer

- Crank-rotation angle transducer

- DC motor/generator

Figure 12 shows the experimental layout with the $\mathrm{CCU}$ on the left hand side and the test section with the HSE on the right.

The HSE has a built-in water jacket that provides the sink (cooler) temperature while the source (heater) temperature is provided by the exhaust gases of a continuous combustion unit (CCU). The finned heat exchanger (hot-end) section of the HSE (refer to Figure 4) is placed in the exhaust system of the CCU in such a way that the exhaust gas is forced through the un-finned (or free flow) area of the heat exchanger by means of guide vanes. The reason for using this approach instead of less complicated options like simply using a Bunsen-burner is to enable closer approximation of the waste heat recovery process as found in internal combustion engines for future research, as well as to provide a uniform heat source for the heater instead of a 'point source' as would be the case with a Bunsenburner.

A direct current (DC) motor, used as a DC generator, was connected to the output shaft of the HSE. This DC generator provided the load for the HSE while the developed electric energy is dissipated by a bank of resistors connected to the generator. A torque sensor is places between the HSE and the DC generator. A speed (revolutions per second) sensor measures the rotational speed of the HSE's fly-wheel. From these two measurements the engine 


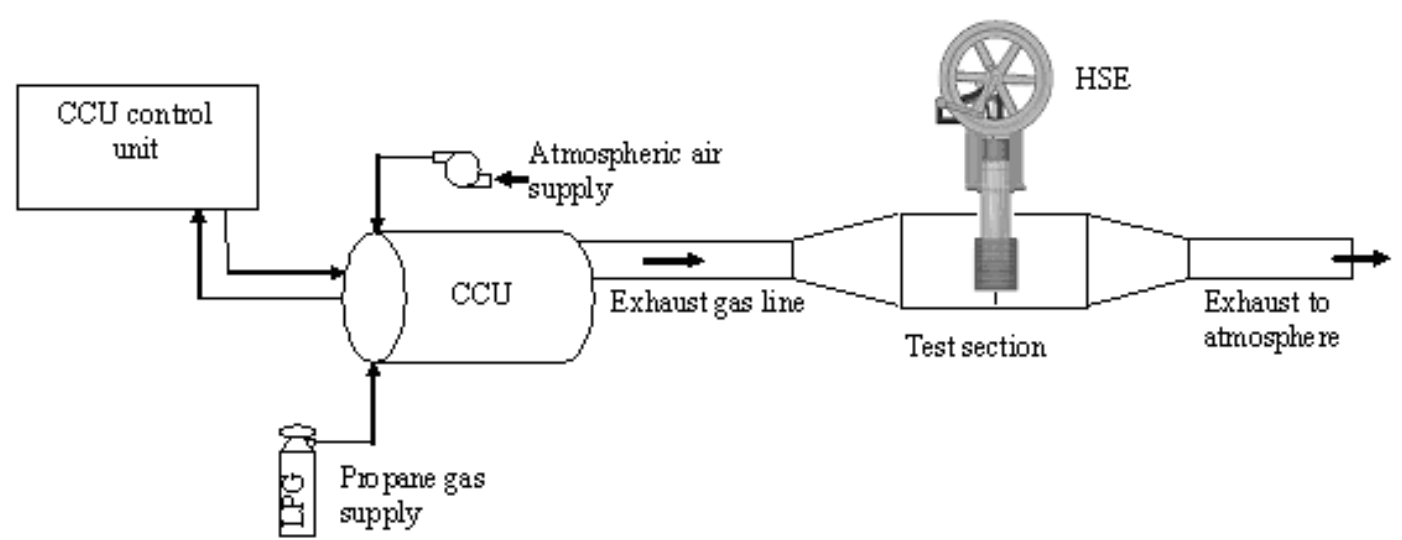

Figure 12: Layout of experimental setup

output power (Watt) can be calculated. The DC motor is also used to run the HSE engine (turn the HSE at the same rpm as operational rpm developed by HSE during tests) in order to measure the frictional, pumping and other losses within the Heinrici engine. This is done by connecting the $\mathrm{DC}$ motor to the output shaft of the HSE at stand still conditions i.e. at constant overall temperature (room temperature) conditions for the HSE engine.

\section{Experimental measurements}

The following losses were measured:

- Crank system frictional losses

- Fan belt and pulley system frictional losses

With the pistons disconnected from the crank system the frictional losses of the rotating components are obtained. Table 6 lists the results of the HSE losses test. Torque required to run the engine at the given operating frequency was used to calculate the power required to overcome the internal losses in the engine according to the $P=\omega T$ relation, where $\omega$ in radians per second is the operating frequency measured at the torque transducer and $T$ $[\mathrm{Nm}]$ the measured torque.

Table 4: HSE losses test data

\begin{tabular}{lc}
\hline & Losses \\
\hline Speed $(\mathrm{rpm})$ & 72 \\
\hline Torque $(\mathrm{Nm})$ & 1.41 \\
\hline Power loss $(\mathrm{W})$ & 10.41 \\
\hline
\end{tabular}

Table 7 compares the power and efficiency of the HSE obtained from experimental tests to that obtained from simulations (refer to appendix B for calculations regarding experimental results). Once again in Table 7, the values stated in brackets for the results of the simple analysis include the nonideal heat exchangers, pumping loss as well as nonideal regeneration effects while the values not in brackets only include the effect of non-ideal heat exchangers.
Table 5: Experimental vs. simulation results

\begin{tabular}{|c|c|c|c|c|}
\hline & erimenta & Simple & Adiabatic & Schmidt \\
\hline Power $[\mathrm{W}]^{*}$ & 18 & $14.2(14.0)$ & 16.2 & 21.81 \\
\hline Efficiency [\%]* & 2.96 & $38.4(3.51)$ & 42.1 & 55.76 \\
\hline \multicolumn{5}{|c|}{$\begin{array}{l}\text { * Results for the Stirling cycle power and efficiency and } \\
\text { not for the total engine thus excluding power required to } \\
\text { overcome losses in the drive mechanism. }\end{array}$} \\
\hline
\end{tabular}

The temperatures $T_{h}$ and $T_{k}$ used as inputs for the simulation program (refer to Table 2 ) are the temperatures experimentally measured as the respective internal hot-end and cold-end gas temperatures and are therefore in correspondence with the input temperatures of the adiabatic analysis, where the heat exchanger gas temperatures, also referred to as $T_{h}$ and $T_{k}$, are fixed. As for the simple analysis, it was found to be difficult to accurately measure the wall temperatures of the heat exchangers and therefore the input temperatures of the simple analysis, namely the heat exchanger wall temperatures referred to as $T_{w h}$ and $T_{w k}$ were set at $T_{h}$ and $T_{k}$ respectively as well. The simple analysis specifically incorporates the effect of non-ideal heat exchangers in order to predict the gas temperatures when given the heat exchanger wall temperatures and it is therefore anticipated that the simple analysis will under-predict the power output of the engine as indicated in Table 7.

Overall it is important to note that the correlation between the predicted results and experimental data is not very close. However, the predicted results are of the same order of magnitude as that of the actual engine. The results therefore do provide useful insight and a meaningful base to further understand the performance of Stirling engines. In this context is good to remember the well known phrase: 'all models are wrong, but some are useful' (e.g. Box et al., 2005). Walker (1980) also states that the real engine always rejects more heat and produces less power than that predicted by the analytical engine. He pointed out that nevertheless 


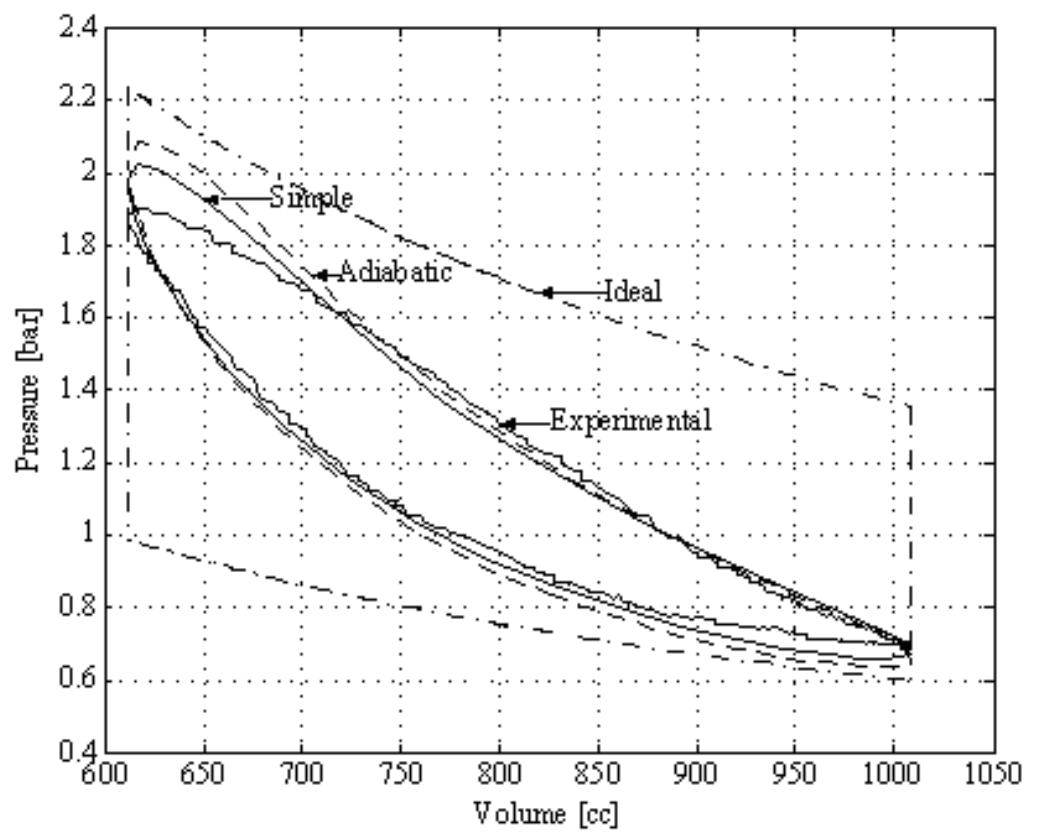

Figure 13: Simulated and measured pressure vs. volume diagrams

practical experience accumulated over many years has made it possible for researchers to provide close and realistic predictions of the performance of Stirling engines, and the Phillips research group was one of the leaders in this aspect.

Keep in mind that the three methods increase in complexity from Schmidt, adiabatic to the simple analysis as more realistic assumptions are made and more non-ideal effects are considered. The predicted results should thus also approach reality in that order. This effect is seen from the $\mathrm{p}-\mathrm{V}$ diagrams presented in Figure 13.

The simple analysis is further away from the lim- its of the ideal $\mathrm{p}-\mathrm{V}$ diagram than that of the adiabatic analysis. As mentioned earlier, this is due to the fact that the adiabatic analysis is a less complex method i.e. it does not take into account the nonideal effects present in the real engine. The simple analysis does consider some of these effects and therefore moves even further away from the ideal situation and similarly the real engine is even further removed from the ideal limits.

Figure 14 shows the simulated and measured pressure vs. crank angle.

The simulated pressure versus crank angle graph for the simple analysis in Figure 14 predicts a high-

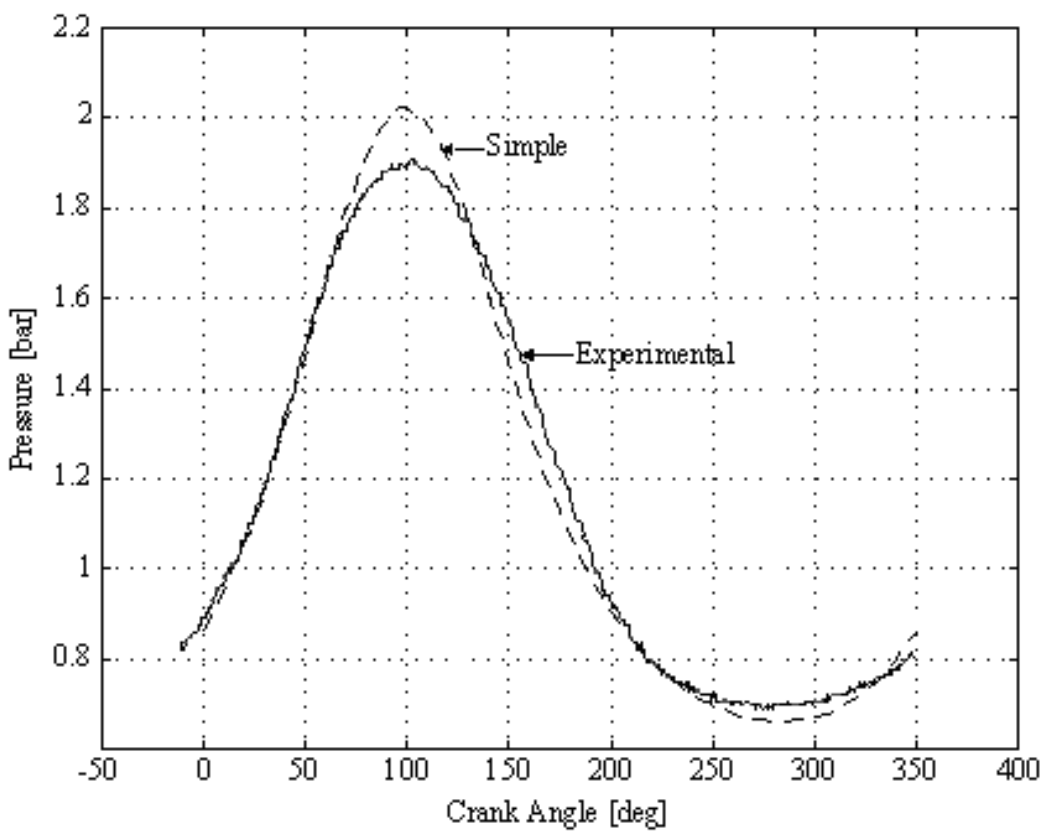

Figure 14: Simulated and measured pressure vs. crank angle 
er peak pressure and a lower trough pressure than for the measured case. This effect can also be seen in Figure 13 where the predicted maximum pressure is higher (at minimum volume) than the experimentally measured value. Similarly, the predicted minimum pressure is lower (at maximum volume) than the experimental value. Inaccurate prediction of fluid density together with the pressure spikes caused by increased heat transfer conditions are reasons for this difference. The lack of ability of the simulation to accurately predict the internal engine pressure can be ascribed to the incomplete incorporation of pumping and fluid friction effects. Shuttle or periodic and alternating direction heat transfer between cylinder walls and gas (and cylinder walls that require temperature gradients in the direction of heat flow) causes increases and decreases in temperatures that in turn cause inaccurate temperature prediction. The latter may then lead to incorrect temperature and pressure calculations creating a positive feedback loop. The interconnection of these two effects (temperature and pressure) complicates the theoretical approach even more (Hargreaves, 1991).

\section{Conclusions and summary}

In summary, three simulation methods of varying complexity, namely the well known Schmidt analysis and two methods developed by Berchowitz and Urieli (1984), namely an ideal adiabatic analysis and the so-called simple analysis was implemented. A few improvements were made and the methods were used to analyse the performance of a Heinrici Stirling engine. The performance of the Heinrici engine was also determined experimentally for the purpose of comparison with the results obtained from the different methods of analysis.

To obtain the internal operating fluid mass of the engine using the method presented by Berchowitz and Urieli (1984), i.e. to solve the problem of the dependency of the equation set on the value of the mass of gas, proved to be fairly simple. The method investigated here by which the results are scaled depending on the difference between simulated and user defined engine pressure is an improvement on the original simulation by Urieli. The simulated results (using the scaling method) provided a satisfactory prediction of the engine's performance when compared to the experimentally determined performance data. The simple analysis provided the closest approximation of the real engine and in accordance with the project's objectives to develop an SE design synthesis tool it is envisaged to further investigate and improve this method in future.

Assumptions made to simplify the theoretical modelling of the system caused inaccurate results when compared to experimental data, however, Figures 13 and 14 and Table 7 indicate that these assumptions still provide feasible answers. Applying the five volume methodology presented by Berchowitz and Urieli (1984) to the actual three volume Heinrici engine seemed unfeasible at first, however, it should be noted that the aim of the analysis procedures presented here is not to simulate the relatively old and inefficient three volume engine topologies but to synthesise and enable analysis during Stirling engine design procedures of the more complex and efficient five volume engine topologies. Due to availability problems and the extensive cost of purchasing modern Stirling engines, the five volume methodology was applied to the available three volume Heinrici engine in order to obtain experimental verification of the methodologies under investigation.

It is concluded that the simple analysis particularly, is suitable as an initial design and analysis tool for Stirling engines.

\section{References}

Berchowitz, D. and Urieli, I. (1984), Stirling Cycle Machine Analysis. Adam Hilger.

Box, J.E.P., Hunter, J.S. and Hunter, W.G. (2005), Statistics for Experimenters. $2^{\text {nd }}$ Ed., Wiley.

Hargreaves, C. M. (1991), The Phillips Stirling Engine. Elsevier, Amsterdam, Netherlands.

Kolin. I. (2001), Ideal Stirling cycle in alpha, beta and gamma engines. Proceedings of the $10^{\text {th }}$ Stirling Engine Conference $24^{\text {th }}-26^{\text {th }}$ September. Osnabruck, Germany.

Lotun, D. (2001), Design and Evaluation through Simulation and Experimental Apparatus of a Small Scale Waste Heat Recovery System. M Sc (Eng) Thesis, Department of Mechanical and Mechatronic Engineering, University of Stellenbosch, South Africa. December.

Morrison, G. (1999), Stirling renewal. Associated Editor, American Society of Mechanical Engineering, feature article. May.

Organ, A. J. (1997), The Regenerator and the Stirling Engine. J W Arrowsmith Ltd.. Great Britain.

Sapa-dpa (2006), New auxiliary turbosteamer to reduce fuel consumption by $15 \%$. Platinum Collection, Supplement to the Cape Argus, 15, February 10.

Van Heerden, L. (2003) Dish Stirling applications for rural development. Eskom Special Edition. Journal of Energy in Southern Africa, July.

Reader, G.T, and Hooper, C. (1983), Stirling Engines. E. \& F.N. Spon, London.

Snyman, H. (2007), Second Order Analysis Methods for Stirling Engine Design. M Sc (Eng) Thesis, Department of Mechanical and Mechatronic Engineering, University of Stellenbosch, April.

Walker, G. (1980), Stirling Engines. Oxford University Press, Oxford.

Wipplinger, K.P.M. (2004), Utilising a High Pressure, Cross Flow, Stainless Steel Fintube Heat Exchanger 
for Direct Steam Generation from Recovered Waste Heat. M Sc (Eng) Thesis, Department of Mechanical and Mechatronic Engineering, University of Stellenbosch, April.

\section{Appendix A: Summary of equation set for ideal adiabatic analysis}

The equation set for the ideal adiabatic analysis presented by Berchowitz and Urieli (1984) is summarised in this appendix. The adiabatic equation set can be divided into several groups of equations, like:

Equations for instantaneous engine pressure and pressure variation:

$$
\begin{aligned}
& p=\frac{M R}{V_{c} / T_{c}+V_{k} / T_{k}+V_{r} 1 n\left(T_{h} / T_{k}\right) /\left(T_{h}-T_{k}\right)+V_{h} / T_{h}+V_{e} / T_{e}} \\
& d p=\frac{\gamma p\left(d V_{c} / T_{c k}+d V_{e} / T_{h} e\right)}{V_{c} / T_{c k}+\gamma\left(V_{k} / T_{k}+V_{r} / T_{r}+V_{h} / T_{h}\right)+V_{e} / T_{h e}}
\end{aligned}
$$

Equations for gas masses in each cell:

$$
m_{i}=p V_{i} /\left(R T_{i}\right), \text { where } i=c, k, r, h, e
$$

Equations for change in mass or mass accumulation in each cell:

$$
\begin{aligned}
& d m_{c}=\left(p d V_{c}+V_{c} d p / \gamma\right) / R T_{c k} \\
& d m_{i}=m_{i} d p / p, \text { where } i=k, r, h \\
& d m_{e}=\left(p d V_{e}+\operatorname{Vedp} / \gamma\right) / R T_{h e}
\end{aligned}
$$

Equations for mass flow over cell interfaces:

$$
\begin{aligned}
& m_{c k}=-d m_{c} \\
& m_{k r}=-m_{c k}-d m_{k} \\
& m_{h e}=-d m_{e} \\
& m_{r h}=m_{h e}-d m_{h}
\end{aligned}
$$

Equations for conditional temperatures (depending on direction of flow):

$$
\begin{aligned}
& \text { if } \quad m_{c k}>0 \text { then } T_{c k}=T_{c}=\text { else } T_{c k}=T_{k} \\
& \text { if } \quad m_{h e}>0 \text { then } T_{h e}=T_{h}=\text { else } T_{h e}=T_{e}
\end{aligned}
$$

Equations for temperature change in the working spaces:

$$
d T_{i}=T_{i}\left(d p / p+d V_{i} / V_{i}-d m_{i} / m_{i}\right), \text { where } \mathrm{i}=e, \mathrm{c}
$$

Equations for energy:

$$
\begin{aligned}
& d Q_{k}=c_{v} V_{k} d p / R-\left(c_{p} T_{c k} m_{c k}-c_{p} T_{k r} m_{k r}\right) \\
& d Q_{r}=c_{v} V_{r} d p / R-\left(c_{p} T_{k r} m_{k r}-c_{p} T_{r h} m_{r h}\right) \\
& d Q_{r}=c_{v} V_{h} d p / R-\left(c_{p} T_{r h} m_{r h}-c_{p} T_{h e} m_{h e}\right)
\end{aligned}
$$

$$
\begin{aligned}
& W=W_{e}+W_{c} \\
& d W=d W_{e}+d W_{c} \\
& d W_{e}=p d V_{e} \\
& d W_{c}=p d V_{c}
\end{aligned}
$$

Thermal efficiency:

$$
\eta=W / Q_{h}=\left(Q_{h}+Q_{k}\right) / Q_{h}
$$

\section{Appendix B: Calculations for experimental results}

Calculation of the experimental Stirling cycle efficiency and the effective exhaust gas heat energy that is available at the hot-end of the Stirling engine i.e. the heat energy in the hot-end wall of the Stirling engine.

Available exhaust gas energy according to Lotun (2001):

$$
Q_{\text {Hwall }}=4600 \mathrm{~W}
$$

Use overall surface efficiency of hot-end fin array ( $\eta_{o}=13.25 \%$ ) from finned hot-end design calculations to obtain available hot-end energy:

$$
\text { Qhot }=\eta_{\circ} Q_{\text {Hwall }}=609.54 \mathrm{~W}
$$

Angular rotation of DC generator (at torque transducer):

$$
\varpi_{\mathrm{DC}}=\frac{2 . \pi .66}{60}=6.912 \mathrm{rad} / \mathrm{s}
$$

Experimentally measured operational torque delivered by HSE (at steady state conditions):

$$
T_{\text {out }}=1.105 \mathrm{Nm}
$$

Experimentally determined system frictional losses:

$P_{\text {loss }}=10.4 \mathrm{~W}$

Experimentally measured work produced by Stirling cycle (Experimental HSE power output):

$$
W_{H S E}=\left(P_{\text {los }} s+\varpi_{D C} . T_{\text {out }}\right)=18.04 \mathrm{~W}
$$

Experimentally determined efficiency of Stirling cycle:

$$
\eta_{\exp }=\frac{W_{H S E}}{Q_{h o t}}=0.0296
$$

